\title{
Prospects and limitations of smart specialization development for Russian regions
}

\author{
Anatoly Gretchenko ${ }^{1,2}$, and Alexander Gretchenko ${ }^{1}$ \\ ${ }^{1}$ Plekhanov Russian University of Economics, 117997, Stremyanny lane 36, Moscow, Russia \\ ${ }^{2}$ Financial University under the Government of the Russian Federation, Russia, Leningradsky \\ Prospekt 49, Moscow, 125993, GSP-3, Russia
}

\begin{abstract}
The article examines the possibilities of the smart specialization strategy for the regions of the Russian Federation as a tool for the complementary development of territories based on knowledge and innovation. The analysis of the application of the smart specialization strategy is carried out on the basis of the author's indicators that have the following functional and target value: the goal setting of the subjects of the Russian Federation, the methodological tools for managing the development of the subject of the Russian Federation, the potential for the implementation of the smart specialization strategy. As an object of research, the documents of strategic planning of the subjects of the Russian Federation until 20202030 are considered. It is concluded that the current nature of the socioeconomic and innovation policy reflected in the documents of the strategic planning of the regions of the Russian Federation does not fully correspond to the principles of the smart specialization strategy, but there is a certain methodological continuity of approaches, which gives grounds to draw conclusions about the possibility of using this methodology.
\end{abstract}

\section{Introduction}

The study of the processes of regional economic development includes the issues of its internal connectivity, the intensity of interaction between actors, and the possibility of their coherent development. In addition to the resource potential of the territories and its use, which determines the level of development of the economic space of the macroregion, an important element is the formation of such a mechanism that would allow, taking into account the strengths of each region, to develop a unified territorial development strategy that enhances the synergistic effects and opportunities for interregional cooperation. At the same time, the proposed model for choosing a strategy, according to the authors of the article [1-4], should be, on the one hand, a clear and simple mechanism for operational management use, on the other - adequately take into account the ongoing regional processes and factors that determine the vectors of development.

It should be noted that the development of regional public policies aimed at strengthening the interconnections between regions, taking into account their local advantages, contributes to the development of technology and knowledge exchange, which is possible with the coordination at the macroregion level of the main and additional industries (activities) that allow developing local competitive advantages through "mutual pollination" of resources 
with the inclusion of less developed territories in the process of technological development. Such an approach abroad is called smart specialization (RIS 3) [5], in which the implementation of the macro-regional approach is provided by the allocation of local resource advantages, technology exchange, concentration on specific breakthrough innovations based on the existing scientific reserve in the territory, as well as the opportunities for economic development of territories through knowledge and innovation.

A significant limitation of the application of smart specialization in the Russian reality is the lack of a consistent comprehensive policy for the development of the innovation potential of the regions, in contrast to the EU, when at the beginning of the last decade, the OECD countries (in particular, the EU) evolutionarily formed and implemented regional development concepts based on knowledge and innovation. The Russian Federation also took steps to develop the innovative potential of the regions, but the existing institutional framework, the principles of inter-budgetary relations, as well as the structural long-term problems of the Russian economy did not allow the formation of a "foundation" similar to the EU countries. This allowed us to conclude that the application of the principles of smart specialization as a tool for the complementary development of the regions of the Russian Federation is potentially possible, but taking into account the institutional and spatial "baggage" of the Russian reality.

The Smart Specialization Strategy (SUS) was proposed by the expert group "Knowledge for Growth" and adopted for implementation in the European Union in 2009. It is aimed at reducing duplication, first of all, of the industrial specialization of the regions and allows to strengthen the historically established economic opportunities of individual territories based on the development of research and industrial potential to increase their global competitiveness.

\section{Research methodology}

The research presented by the authors of the article confirms the hypothesis that the smart specialization approach can be used at the regional level as a tool for strategic planning of regional development based on knowledge and innovation to increase their global competitiveness, taking into account the specifics and peculiarities of the Russian Federation, as part of strengthening the processes of coherent development of regions [6]. Based on this, in this article it seems appropriate to test the SUS in the regions of the Russian Federation in order to develop a mechanism to ensure their competitiveness. There are methodological grounds for this: the Russian regions are significantly differentiated by the level of socioeconomic development (as well as the EU countries), there is an uneven distribution of production forces (as in the EU countries, taking into account the former Soviet principles of placement), the regions have the ability (according to the law on Strategic Planning of the Russian Federation [7]) to independently develop regulatory documents regulating innovation.

The approach of E. Kutsenko is used as the main basis for comparison. with the addition of the author's indicators that examine the presence of elements of smart specialization in strategic planning documents and the tools of regional planning and management used, which would correlate with methodological approaches and be suitable for developing a smart specialization strategy for the regions of Russia. The study used the regulatory documents of the strategic planning of the Russian regions (as on January 2020) from open sources. The authors developed the following methodological tools for assessing the potential of implementing the Smart Specialization Strategy to improve the competitiveness of regions (Table 1). 
Table 1. Indicators for assessing the development potential of Russian regions based on knowledge and innovation (compiled by the authors)

\begin{tabular}{|l|l|}
\hline \multicolumn{1}{|c|}{ Name of the indicator group } & \multicolumn{1}{c|}{$\begin{array}{c}\text { Functional and target value of } \\
\text { indicators }\end{array}$} \\
\hline $\begin{array}{l}\text { Indicators that reflect the priority of the region's } \\
\text { development based on knowledge and innovation }\end{array}$ & $\begin{array}{l}\text { Goal setting of the subjects of the } \\
\text { Russian Federation }\end{array}$ \\
\hline $\begin{array}{l}\text { Indicators reflecting the continuity of methodological } \\
\text { tools for knowledge-based development and innovation }\end{array}$ & $\begin{array}{l}\text { Methodological tools for managing the } \\
\text { development of the subject of the } \\
\text { Russian Federation }\end{array}$ \\
\hline $\begin{array}{l}\text { Indicators reflecting the applicability of the use of } \\
\text { the "smart" Specialization Strategy in the } \\
\text { development of regions }\end{array}$ & $\begin{array}{l}\text { Potential for implementing a Smart } \\
\text { Specialization Strategy }\end{array}$ \\
\hline
\end{tabular}

This set of indicators reflects the readiness and awareness of the need to transform regional development, which includes a change of priorities, acceleration of internal and external network interaction, and the inclusion of key actors in the process of managing territorial development (Table 2).

Table 2. Criteria for assessing the development potential of Russian regions based on knowledge and innovation (using the smart specialization methodology, compiled by the authors using the approach [8])

\begin{tabular}{|l|l|}
\hline $\begin{array}{c}\text { Name of the potential } \\
\text { development indicator }\end{array}$ & \multicolumn{1}{c}{ Decoding the potential development } \\
indicator
\end{tabular}
and innovation

Documents of strategic planning of the subject of the Russian Federation defining priorities of development on the basis of knowledge and innovations

The presence of a legislative act of the subject of the Russian Federation that encourages innovation

The presence in the subject of the Russian Federation of the system of support of innovative activity, the Development Institute for support of innovative activity

The presence of innovation clusters in the subject of the Russian Federation

Participation and victories of enterprises of the subject of the Russian Federation in the competitions " Development-NTI (according to the data of 2020)
The presence of dedicated branches of specialization in the region that meet the priorities of regional and national development

The complexity of the regulatory and legal documents of the subject of the Federation, highlighting the priorities of innovative development of the region Analysis of external challenges and compliance of the measures taken with the development of new areas that allow us to join the global agenda

The existence of a separate legislative act that encourages the development of innovative activities in the region

Allocation of priority industries in accordance with specializations that use tax incentives in the implementation of innovative activities

Inclusion of innovative infrastructure actors in the regional innovation system

Interaction of innovative infrastructure actors with the local business community

Formation of a network of innovation clusters, unions, networks, alliances that reflect the main economic specializations of the region

Determining the level of development of the business environment in the region

Involvement of the business community in development institutions support programs 


\begin{tabular}{|l|l|}
\hline & $\begin{array}{l}\text { Interaction of government authorities with } \\
\text { representatives of the business community through } \\
\text { involvement in obtaining financial support }\end{array}$ \\
\hline $\begin{array}{l}\text { The region's place in the Rating of } \\
\text { innovative development of the subjects } \\
\text { of the Russian Federation (2020) }\end{array}$ & $\begin{array}{l}\text { Pe The effectiveness of the innovation activity of the } \\
\text { subject of the Russian Federation }\end{array}$ \\
\hline
\end{tabular}

\section{Indicators reflecting the continuity of methodological tools for knowledge-based development and innovation}

Methodology used for analysis in the documents of the strategic planning of the subject of the Russian Federation, determining the priorities of development based on knowledge and innovation
Availability of an analysis of the strengths and weaknesses of the region

Description of the innovation potential and areas of specialization of the region

Comparison with other regions in similar areas of economic specialization

Description of the directions of development of interregional cooperation

Using scenario forecasting methods

Indicators reflecting the applicability of the use of the "smart" Specialization Strategy in the development of regions

Involvement in the development process based on knowledge and innovation of all actors

Formation of the" image of the future " of the region

Selecting priorities for industry specialization

knowledge and innovation
Involvement of a wide range of stakeholders in the development of the regional development strategy, industry strategies: government, business, science, civil society, experts (including from other countries/regions) [8]

Formation of the service subsystem of the region: the use of public, interactive formats of interaction between the state, business and citizens in the process of strategy development [8]

Development of specific measures to develop the desired image of the future of the region, attractive to the population, business of the region

Taking into account the analysis of the context of the external and internal environment of the region, its resource potential, the level of scientific and technological development, the main production specializations in the image of the future

Identification of a limited number of specific areas of specialization of the region (actual or potential) for the development of innovations and the formation of unique competitive advantages

Linking with national priorities in the field of science and innovation, positioning the selected priorities in relation to general-purpose technologies [8]

The presence of a critical mass of selected priorities with resources and entrepreneurial potential, the concentration of resources on the selected priorities

Identification of technological limitations of the development of priority industries, the level of research potential

Determining the list of critical areas of scientific research in the region with the involvement of the business community and taking into account market prospects 
Availability of a system for monitoring and evaluating the achievability of development indicators based on knowledge and innovation
The presence of a system of indicators that reflect the level of technological, innovative and research development of the region (including methods for assessing the organizations of infrastructure, higher education, innovative potential of the business community, etc.).

The authors analyzed the strategic planning documents according to the proposed indicators [9-11]. The indicators analyzed in Table 2 allow us to conclude that there are priorities for development based on knowledge and innovation in the goal setting of the subjects of the Russian Federation through a set of qualitative indicators related to the programmed tasks of innovative development and actions taken by the authorities to stimulate innovation processes, which is reflected in the ratings of innovative development and the activity of regional actors in strategic programs.

\section{Results of the study}

According to the results of the analysis, it can be concluded that, in general, all subjects of the Russian Federation are aware of the need for development based on knowledge and innovation, based on the presence in almost all regions of legislative acts that are aimed at stimulating innovation activity through measures of state support and tax incentives. Thus, in the course of the study on the example of the Siberian Federal District (SFO), it was found that the Tomsk, Novosibirsk regions, and Krasnoyarsk Territory are naturally the most included in the development agenda on the basis of knowledge and innovation in this district, which is due to the historically established structure and the presence of a critical mass of universities, research institutes, as well as innovative territorial clusters, while each region has its own specifics. It is possible to note the activation of innovative activities in the Kemerovo and Irkutsk regions.

Thus, the Kemerovo region is the most active in developing the necessary regulatory support for innovation activities, which is represented in a large number of regulatory documents that reflect these priorities, despite the lack of a powerful resource potential (unlike the Tomsk and Novosibirsk regions) in the form of research universities and research institutes with a long history and the predominance of traditional industry. Cluster policy is being actively implemented in most regions. The Novosibirsk Region has achieved the greatest results here, where the Cluster and Park Policies have been approved in a single key, as part of the implementation of the Reindustrialization Strategy. Regions with less groundwork in this area, the Republic of Tyva, Khakassia, Altai, also formulate an agenda of the intention to create clusters in priority industries.

Most regions have a "classic" set of regulatory documents defined by the Federal Law "On Strategic Planning in the Russian Federation", but many regions additionally implement state programs for the development of the innovation economy and develop a number of additional regulatory documents (Investment policy, Cluster Policy, the Concept of Development of Foreign Economic and Interregional Activities), which allows us to conclude that there is a need to implement a model of development based on knowledge and innovation. The analysis of the main methodological tools used for analysis in strategic planning documents at the level of the subjects of the Russian Federation shows that in most regions an analytical base has been collected on the weaknesses and strengths of the territories, as well as on those potential competitive advantages that can be identified as development priorities, but only in the Kemerovo region the opportunities for interregional cooperation are highlighted and the strengths and weaknesses that form the challenges are objectively described, overcoming them can lead the region to a fundamentally different level of development. 
In general, it can be concluded that in most regions the necessary analytical base has been formed for the development within the framework of the "smart" specialization model, at least the block related to the analysis of the resource potential. A significant disadvantage may be the heterogeneity of the information provided and the lack of a single methodological tool and format for providing information, which significantly complicates the work on forecasting in a single key, which can be overcome through the formation of common methodological principles (following the example of regional strategies under RIS3).

The study analyzed the indicators used in the monitoring of the RIS3 Strategy, which allows us to assess the possibility of implementing this strategy at the regional and macroregional level in the Russian Federation.

Summarizing the results obtained, we can conclude that most regions have developed regulatory and legal documents that form the development based on knowledge and innovation as priorities, and almost all of them have identified priority industries that correspond to traditional industries developing in this region. However, in general, there is a weak involvement of regional actors in the adoption of the strategy and the formation of public consensus in the development of the" image of the future " of the region, the main priorities of regional development, as well as in the selection of basic key specializations. In the Tomsk, Novosibirsk and Krasnoyarsk regions, there is a wide range of regulatory planning documents with additional development programs in the form of strategies for the reindustrialization of Siberia, etc., where a deep analysis of technological constraints and barriers to the development of the region, including innovation, is carried out, industry priorities are identified, based on the methods of calculating the intersectoral balance developed over many years by the institutes of the Siberian Branch of the Russian Academy of Sciences. Various stakeholders are actively involved in the development of development programs of both a region-wide nature and industry prospects, which can be noted based on the results of the analysis of publications in the media and accounting documents. The formulation of the "image of the future" is poorly reflected in the planned activities and is formulated as a model of an attractive future. The choice of priority areas in most regions, as a rule, is linked to the current structure of the industry, which is supported by the calculations of the OKVED and reflects either a link to large industrial conglomerates of the old industrial regions (Irkutsk, Omsk, Kemerovo regions). The model of development of these regions suggests an innovative modernization of resource-producing technologies, or reflects the agricultural specifics of the southern regions (without taking into account external global challenges and development priorities of the Russian Federation).

\section{Summary}

In general, a feature of the smart specialization strategy is the complexity of using all the components, starting from the monitoring system and the governing body and ending with taking into account the possibilities of cluster and interregional interaction when choosing the types of economic specialization of regions. With the high quality of strategic planning documents in certain regions, there is clearly a high competitive environment in which the regions are forced to develop in the current situation, which does not allow for the formation of synergistic advantages. Even the cluster approach in most documents is implemented through the development of regulations on the functioning of clusters within the region, without reference to interregional and inter-cluster interaction. At the national level, it is important to change the inertia scenario of interaction between regions, which excludes cooperation and forms exclusively competitive relations. The unification of requirements and methodological support at the national level would, on the one hand, strengthen the mechanism of transparency and understanding of long-term policy trends of top-level actors, on the other hand, it would partially involve the regions in the mechanism of joint 
development, borrowing best practices and strategies and opportunities for the development of the mechanism of technological arbitration (imitation) at the regional level.

\section{Conclusion}

Thus, we can conclude that it is possible to apply the Smart Specialization Strategy for implementation at the macro-regional level, which is due to the presence of an analytical information base, awareness of the need for development) based on knowledge and innovation. For its full application, it is necessary to significantly refine the methodology for assessing regional potential, formulate a single principle for the formation of industry specializations, and also propose indicators for monitoring the activation of network intraand interregional interaction with access to its own indicators for monitoring development based on knowledge and innovation, taking into account the specifics of Russian reality, the level of development of the institutional component.

This article was prepared as part of the government contract as requested by the Ministry of Science and Higher Education of the Russian Federation on the subject formulated as «Structural changes in economy and society as a result of achieving the target indicators of National projects, which provide opportunities to organize new areas of social and economic activity, including commercial, both in Russia and abroad» (project No. FSSW-2020-0010).

\section{References}

1. A. I. Gretchenko, A.A. Gretchenko, European Proceedings of Social and Behavioural Sciences, 79, 430 (2019)

2. A.I. Gretchenko, E.E. Nikitskaya, A.A. Gretchenko, O.G. Demenko, Journal of Advanced Research in Law and Economics, 9(3(33)), 481 (2018)

3. A.I. Gretchenko, A.A. Gretchenko, Lecture Notes in Networks and Systems, 161, 283 (2021)

4. N. Moiseev, B.A. Akhmadeev, Journal of Interdisciplinary Economics, 29(2), 176 (2017)

5. D. Foray and oth. Guide to Research and Innovation Strategies for Smart Specialisations (RIS

https://ec.europa.eu/regional_policy/sources/docgener/presenta/smart_specialisation/s mart_ris3_2012.pdf

6. G. Beliakov, A. Gretchenko, A. Ryzhaya, A.Shpak, S. Belyakov, International Journal of Supply Chain Management, 8(6), 1035 (2019)

7. The Federal Law on Strategic Planning in the Russian Federation was adopted by the $\begin{array}{lllll}\text { State Duma June } & 2014 .\end{array}$ https://www.consultant.ru/cons/cgi/online.cgi?rnd=6C6438F19F23923E41C6C9F2DC 8A932F\&req $=$ doc $\&$ base $=$ LAW $\& n=358824 \&$ REFFIELD $=134 \&$ REFDST $=100350 \& R$ EFDOC $=314301 \&$ REFBASE $=$ LAW \&stat $=$ refcode $\% 3 D 16876 \% 3$ Bindex \%3D426\#bk1 g23ayvo

8. E. Kutsenko, E. Islankina, A. Kindras, Foresight and STI Governance, 12(1), 25 (2018)

9. B.A. Akhmadeev, S.V. Manakhov, Espacios, 39(18), 31. (2018)

10. A.I. Gretchenko, I.V. Gorokhova, O.G. Demenko, A.A. Gretchenko, Journal of Advanced Research in Law and Economics. Quarterly, 9(4), 1243 (2018) 
11. O.K. Lukhovskaya, L.I. Sharova, A.I. Gretchenko, Izvestiya vysshikh uchebnykh zavedeniy. Technology of the textile industry, 5(383), 5 (2019) 